\title{
A gerontologia como campo do conhecimento científico: conceito, interesses e projeto político
}

\author{
Gerontology as a field of scientific knowledge: \\ concept, interests and political project
}

Shirley Donizete Prado 1

Jane Dutra Sayd 2

\footnotetext{
1 Departamento de Nutrição Social, Instituto de Nutrição da Uerj. Rua São Francisco Xavier 524, 12 o andar, Bloco D, Pavilhão João Lyra Filho, Maracanã, 20550-900, Rio de Janeiro RJ. shirley_prado@terra.com.br

2 Departamento de

Planejamento e

Administração em Saúde,

Programa de Pós-

Graduação em Saúde

Coletiva do Instituto

de Medicina Social, Uerj.
}

Abstract The article discusses gerontology's intention to become the science of aging in Brazil. We considered Stengers's idea that the development of a concept and the emergence of interests in different sectors of society concerned with a political project are the foundations for the establishment of a scientific field. We have identified important conceptual limitations involving old age and ageing delimitations, as well as other problems concerning hierarchies between inner spheres in gerontology and in other knowledge fields. Despite the important interests aroused by old age, gerontology seems to be on a very limited level as scientific park and as critical mass for the production of advanced research. It seems that present elaboration of a political process for gerontology lays on the attempt to incorporate epistemological discourse within a perspective which make us think of the need of deepening theoretical approach about the concept it intends to grasp, at the risk of failing in the organization of an important group of Brazilian researchers inserted in the international scene of scientific production on ageing individuals.

Key words Aging, Aged, Gerontology, Geriatrics, Scientific production
Resumo Discutimos a gerontologia em suas pretensões de constituir-se como a ciência do envelhecimento no Brasil. Consideramos o pensamento de Stengers, que defende a idéia de que o desenvolvimento de um conceito e o despertar de interesses em diferentes setores da sociedade, articulados a um projeto político, constituem-se em pilares fundamentais para o estabelecimento de um campo científico. Identificamos limitações conceituais importantes envolvendo a delimitação da velhice e do envelhecimento, bem como problemas referentes a hierarquias entre domínios internos à gerontologia e a outros campos do conhecimento. A despeito dos importantes interesses suscitados quando a velhice está em questão, a gerontologia parece estar num plano muito limitado como parque científico e como massa crítica para a produção de pesquisas de ponta. Parece-nos que o momento atual de elaboração de um projeto politico para a gerontologia está situado no espaço da tentativa de incorporação do discurso epistemológico, a partir de uma perspectiva que nos faz pensar na necessidade do aprofundamento da abordagem teórica acerca do conceito que pretende capturar; sob pena de não avançar na constituição de um importante conjunto de pesquisadores brasileiros de ponta, inseridos no cenário internacional da produção de conhecimento sobre o ser que envelhece.

Palavras-chave Envelhecimento, Idoso, Gerontologia, Geriatria, Produção científica 


\section{Introdução}

Estudos que realizamos recentemente indicam que a pesquisa sobre envelhecimento no Brasil corresponde à atividade impulsionada a partir da década de 1980. Há um pequeno número de grupos de pesquisa especificamente dedicado à temática, cujos pesquisadores carecem de titulação acadêmica mais elevada, o que está estreitamente relacionado com a reduzida participação de estudantes de pós-graduação stricto sen$s u$ nesses grupos. Há poucos programas de pós-graduação stricto sensu voltados especificamente para questões relativas ao envelhecimento - três programas em gerontologia, dos quais apenas um com doutorado, e mais três que contam com áreas de concentração afins à temática. Dos cinco periódicos especializados em atividade, apenas um se encontra em indexação na Base de Dados Literatura LatinoAmericana e do Caribe em Ciências da Saúde, referência básica de qualidade acadêmica de publicações seriadas em saúde no Brasil1, 2, 3, 4, 5 .

São indicações de que deverá ser bastante longo o caminho que a gerontologia e a geriatria brasileiras têm a trilhar para que venham a se estabelecer como campos dinâmicos e consolidados da pesquisa. No seu conjunto, os resultados poderiam ser entendidos como indicadores de uma área de conhecimento nova, em formação. Esse tipo de leitura, em algum grau, está presente na literatura brasileira especializada. Em Lopes 6 encontramos a transcrição das palavras de um entrevistado, dirigente da Sociedade Brasileira de Geriatria e Gerontologia (SBGG), que fala sobre as perspectivas da gerontologia como ciência: Não há uma teoria unificadora sobre nada na velhice. Há mil modelos, muita gente falando a mesma coisa com termos diferentes, estes são obstáculos; no domínio científico, são os mais sérios para a constituição da gerontologia como um corpo organizado de conhecimento. Mas é uma questão de desenvolvimento, pois ela é nova ainda (grifo nosso).

São palavras importantes, porque estão presentes no fechamento de um livro intitulado $O s$ desafios da gerontologia no Brasil, o que lhes conferem caráter conclusivo. Palavras que se encontram estruturadas em dois blocos: um primeiro, que nos fala de obstáculos conceituais para a constituição da gerontologia como domínio científico; e um segundo, que parece corresponder ao caminho de solução para os obstáculos identificados - ou seja, a idéia da gerontologia como uma ciência em sua "juventu- de”, e que virá a amadurecer, a se desenvolver com o passar do tempo.

Essa leitura nos trouxe uma inquietação, posto que dá margem a parecer que estamos diante de uma imagem relativa ao curso do desenvolvimento de um novo campo da ciência: a idéia de que, se há problemas na formulação, na concepção do novo campo, os obstáculos serão superados pelo trabalho dos cientistas, que gradualmente desenvolverão os elementos que são, hoje, ainda embrionários. Um tom otimista que parece não considerar possibilidades de que esse percurso venha a enfrentar percalços, problemas, dificuldades maiores; como se, linearmente, esse campo novo tenha por futuro seu pleno desenvolvimento a partir do trabalho dos pesquisadores que se dedicam a essa temática. Tal inquietação nos levou a buscar outras perspectivas, através de autores que estudam e constroem teorias relativas à constituição de novos domínios científicos.

Buscamos, assim, trabalhar a partir das abordagens presentes no pensamento de Isabelle Stengers ${ }^{7}$, em suas discussões sobre ciências e poderes, que incluem incursões sobre a dinâmica do surgimento de novos campos científicos e as relações que estabelecem entre si e com aqueles já existentes, consolidados ou não. A autora considera que é bastante complexo o conjunto de questões que envolvem a constituição de um campo científico e destaca que, centralmente, o desenvolvimento de um conceito e o despertar de interesses em diferentes setores da sociedade, articulados a um projeto político, constituem os pilares fundamentais para seu estabelecimento. Assim, a consolidação de um campo da ciência não dependeria apenas do mundo interno ao campo em formação, ou seja, da solidez do trabalho que os cientistas desenvolvem em seu interior. Estaria em questão o encontro com outros campos, de cujas confrontações resultariam novos limites e fronteiras. Isso se dá em meio a uma rede de interesses sociais na qual se realiza a capacidade de convencimento dos demais, de que os conceitos propostos são sólidos e têm poder explicativo.

\section{Envelhecimento e velhice Gerontologia e geriatria Conceitos e hierarquias entre domínios}

Nas palavras de Stengers: Um conceito sempre organiza a um só tempo aquilo de que trata e a 
hierarquia das ciências no domínio que ele organiza ${ }^{7}$

Buscando compreender aspectos relativos aos conceitos centrais de que tratam a geriatria $\mathrm{e}$ a gerontologia, encontramos em Groisman 8, 9 importante revisão bibliográfica internacional sobre o tema e enérgica crítica às pretensões de cientificidade da geriatria e da gerontologia. Nesses estudos, evidenciam-se indicações relativas à inexistência tanto de uma conceituação clara quanto de limites que poderiam descrever esse campo como uma ciência do envelhecimento, além de considerações referentes a um elevado grau de incerteza e de controvérsias em relação às bases da gerontologia, que corresponderiam a um conjunto pouco específico de teorias do envelhecimento.

Para o caso brasileiro, Sá10, discutindo os fundamentos epistemológicos e os conceitos de gerontologia, levanta várias definições e nos diz que se continuarmos a analisar os demais conceitos, verificaremos que existe uma certa frouxidão no uso de noções referentes à natureza científica da gerontologia.

A menção aos aspectos biopsicossociais do envelhecimento é recorrente nos trabalhos publicados no Brasil. Entretanto, ao buscarmos identificar o conceito de envelhecimento na literatura nacional, este é encontrado em termos biológicos. Nas palavras de Neri11, o envelhecimento compreende os processos de transformação do organismo que ocorrem após a maturação sexual e que implicam a diminuição gradual da probabilidade de sobrevivência. É interessante notar que o processo de envelhecimento engloba a velhice que, distintamente, é definida em termos mais amplos: É a última fase do ciclo vital e é delimitada por eventos de natureza múltipla, incluindo, por exemplo, perdas psicomotoras, afastamento social, restrição em papéis sociais e especialização cognitiva. À medida que o ciclo vital humano se alonga, a velhice passa a comportar subdivisões que atendem a necessidades organizacionais da ciência e da vida social.

Além de termos de lidar com dois conceitos enunciados em campos distintos - o envelhecimento, definido em termos biológicos, e a velhice, delimitada por eventos de natureza múltipla -, Veras 12 nos indica que se tomarmos apenas os limites da velhice para análise, já estaremos diante de um grande problema. Em suas palavras: Nada flutua mais do que os limites da velhice em termos de complexidade fisiológica, psicológica e social. Uma pessoa é tão velha quanto suas artérias, seu cérebro, seu coração, seu mo- ral ou sua situação civil? Ou é uma maneira pela qual outras pessoas passam a encarar certas características que classifica as pessoas como velhas?

Voltando a Stengers, o desenvolvimento de um conceito constitui um dos pilares fundamentais para o estabelecimento de um campo científico. Para o caso da geriatria e da gerontologia, aquilo de que tratam parece que ainda não está suficientemente claro. Consideramos que essa insuficiência conceitual se coloca hoje como um limitante fundamental para que se possa falar em estabelecimento da geriatria e da gerontologia como campos científicos.

Prosseguindo com Stengers, no que se refere à hierarquia das ciências no domínio que o conceito organiza, os problemas com o conceito de envelhecimento trazem para a geriatria e a gerontologia implicações diretas no estabelecimento de hierarquização interna a esses domínios, bem como no que se refere a outros campos do conhecimento.

No plano internacional, a gerontologia designa o que corresponderia ao estudo do envelhecimento: em seu interior estão abrigadas a geriatria, voltada para a prevenção e o tratamento das doenças na velhice, e a gerontologia social, constituída de diversas áreas como psicologia, serviço social, direito, entre outras. Em que pese alguma coincidência de termos para denominar ao mesmo tempo o todo e a parte, a abrangência maior da gerontologia fica atestada pelo nome da entidade que a representa mundialmente: Associação Internacional de Gerontologia.

Embora a literatura nacional corrobore as definições acima11, outros elementos devem ser considerados. Observemos que a Sociedade Brasileira de Geriatria - fundada em 1961, filiada à Associação Médica Brasileira e que, em 1968 , passou a se denominar oficialmente Sociedade Brasileira de Geriatria e Gerontologia -, embora admita membros associados de outras categorias profissionais, tem sua presidência exercida exclusivamente por médicos. Trata-se de uma história marcada por acirradas disputas corporativas, que incluíram, inclusive, a criação, por duas vezes, da Associação Nacional de Gerontologia 6 .

Groisman ${ }^{9}$ também assinala a divisão entre geriatras e gerontólogos, bastante presente na organização de eventos científicos da SBGG. Essa demarcação de campos não corresponde exatamente a uma unanimidade, e são recorrentes os discursos que advogam um tratamento que integre geriatria e gerontologia. Entre- 
tanto, desejamos assinalar que, mais do que uma delimitação de domínios estabelecida como conseqüência de conceitos fundantes, a gerontologia (no sentido amplo) parece ter sua hierarquia interna estabelecida muito mais por influência das identidades profissionais.

A frouxidão conceitual na gerontologia, anteriormente assinalada em Sá10, parece que também se manifesta nas suas relações com outros campos do conhecimento, como podemos depreender do trecho que se segue: Quando um psicólogo-gerontólogo, por exemplo, atua no campo do envelhecimento, a quem de fato corresponde o processo de intervenção - à psicologia ou à gerontologia? [...] Existem de fato uma teoria e uma metodologia próprias da gerontologia?

Vale aqui registrar que uma parcela importante da produção científica brasileira sobre envelhecimento não pode ser classificada como gerontológica, pois são estudos que se encontram conceitual e metodologicamente situados em outros campos do conhecimento; e nem tampouco seus autores seriam identificados como geriatras ou gerontólogos 13 .

Mesmo as iniciativas voltadas para os idosos nem sempre se caracterizam como gerontológicas, como se constata nas palavras dos dirigentes da Universidade Aberta da Terceira Idade, por exemplo: É importante destacar que o modelo desenvolvido na Unati/Uerj se fundamenta no campo da saúde coletiva, embora tenha com a gerontologia uma afinidade de saberes e práticas 14 .

Outro tipo de abordagem pode ser encontrado em Sfez ${ }^{15}$, que discute os caminhos que a ciência vem trilhando, orientada para um futuro próximo e distante: uma marcha rumo à utopia da saúde perfeita, entendida como uma ideologia que o autor busca identificar e criticar. Encontramos aí alguns elementos que tomamos como contraponto às perspectivas da geriatria e da gerontologia na abordagem do envelhecimento. Sfez refere-se aos projetos $G e$ noma, Biosfera II, Artificial Life e Cyborg, que, pela própria dimensão de suas concepções, contam com recursos de grande monta, pesquisadores renomados e reconhecidos internacionalmente, mobilizando interesses globais. $\mathrm{O}$ primeiro, originariamente americano, ganha o mundo ao pretender o mapeamento genético completo da espécie humana, a caminho da eventual eliminação dos defeituosos e do aperfeiçoamento dos demais. Resultado: o homem perfeito, o aumento da duração da vida e, quiçá, a imortalidade. O segundo, uma imensa re- doma construída no deserto do Arizona, onde os biosferianos devem viver sem ajuda externa e contribuir na geração de conhecimento: perspectivas para a vida no espaço depois da explosão do Sol ou de outra forma de destruição da Terra. Em Artificial Life, cérebros sem corpo conquistarão a vida eterna por meio da conexão com computadores. E, finalmente, Cyborg: organismo cibernético puro, sem doenças, sem sexo, sem contradições: o limite ideal das novas utopias. Por meio desses projetos - em andamento efetivamente vigoroso -, o autor nos fala da construção de caminhos para a purificação geral do planeta e do homem, retomando os mitos mais ancestrais: Adão, o elixir da juventude, a pedra filosofal, a vida sem dor, sem velhice, sem morte.

Aproximando-se de Sfez quanto ao papel da ciência na reorganização da vida, encontramos Featherstone \& Hepworth ${ }^{16}$, que, tratando especificamente do envelhecimento, trazem para nossas discussões alguns elementos importantes, em especial sobre o papel da tecnologia. Entendem que, nos dias atuais, ela parece estar a serviço de uma sociedade que reafirma desejos imemoriais de viver na juventude e de afastamento da degeneração física e da morte. Os autores consideram o crescimento das tecnologias de informação como estratégicas e definidoras de outros campos tecnológicos. No que se refere à comunicação, entendem que o desenvolvimento da realidade virtual associada à internet possibilitará a construção de novas formas de contato social, independentes da presença física. No ciberespaço, a identidade poderá corresponder a qualquer imagem deseja$\mathrm{da}$, abrindo espaço para uma verdadeira infinidade de selves para uma mesma pessoa, em interações totalmente personalizadas, únicas. Afastando-se do modelo de comunicação de massa, esse tipo de tecnologia propiciará a diluição do modelo de velhice e de envelhecimento presente no curso de vida moderno, o que vale para todos os grupos sociais. Também o acesso a um grande volume de informações sobre o corpo - o que em geral não está largamente disponível - possibilitará um automonitoramento do corpo e do processo de envelhecimento. Quanto às tecnologias de intervenção no corpo biológico, a cirurgia plástica, os transplantes e implantes, as clonagens e as interconexões com máquinas trarão transformações corporais de grande repercussão sobre os limites do corpo, os selves, o tempo de vida, a vida e a morte. 
Tanto em Sfez como em Featherstone \& Hepworth encontramos possibilidades de reconstruções da vida e temos o envelhecimento tratado pela ciência e pela tecnologia por um outro ângulo, que se distingue radicalmente da gerontologia. Em primeiro lugar, porque não há aí qualquer pretensão de estabelecimento de um campo novo do conhecimento voltado para o envelhecimento. Em segundo, porque os conceitos em questão, para o caso de haver concorrência na tentativa de captura do envelhecimento, correspondem ao seu inverso - à vida eterna, à juventude -, à sua negação. Em terceiro lugar, porque a partir dessa abordagem trazida por Sfez, podemos pensar que o envelhecimento é muito maior do que possa conceber a gerontologia. Nesse sentido, vale registrar que apenas cerca de $10 \%$ dos temas estudados nos grupos de pesquisa cadastrados no Conselho Nacional de Desenvolvimento Científico e Tecnológico (CNPq) encontram-se situados no espaço do envelhecimento biológico; todos os demais se voltam para a velhice ${ }^{3}$. Isso, por sua vez, conduznos à idéia de que a gerontologia, em suas tentativas de captura do envelhecimento, tenha caminhado, ao menos até agora, muito mais no espaço da velhice, do envelhecimento dos velhos, do envelhecimento na velhice.

Por outro lado, visualizamos espaços comuns entre Sfez e Featherstone \& Hepworth, e as perspectivas gerontológicas no trato dos idosos: vários autores, como Debert17, Lima 18 ou Groisman 8, 9, entre outros, discutem a leitura da velhice na gerontologia, indicando tendência velada à negação de seu próprio objeto. Uma das formas de manifestação dessa perspectiva pode ser observada na nomenclatura largamente presente na literatura gerontológica para denominar as pessoas que constituem seu objeto: "idoso", "pessoa idosa” ou variações como "idade madura", "adulto maduro", "adulto maior", "terceira idade", "sênior", além de neologismos que mostram bem o caráter de vida ativa, autônoma e participante que essas pessoas devem levar, como "felizidade", "melhoridade", "maioridade", entre outras. Poucos são os que usam a palavra velho, que, aliás, utilizada como palavra-chave nas buscas que realizamos em bases de dados bibliográficas, ou no Diretório dos Grupos de Pesquisa do CNPq, trouxeram os piores resultados em termos de recuperação de informações gerontológicas, valendo o oposto para palavra-chave idoso.

Outra forma de expressão dessa mesma negação parece estar presente na prática e no dis- curso gerontológicos. Debert ${ }^{19}$ chama a nossa atenção para uma contradição fundamental da gerontologia, que, ao buscar a construção de novas visões para os velhos, caminha claramente para a transformação dos gerontólogos em profissionais do combate à velhice. Nessa mesma linha de pensamento, Lima ${ }^{18}$, discutindo novas formas de gestão da velhice, enfatiza a desconstrução de imagens estereotipadas e a valorização de aspectos subjetivos - como se sentir jovem - que favorecem a possibilidade de as pessoas da terceira idade enfrentarem de modo bem-sucedido o seu envelhecimento. Afirma o autor em seus estudos sobre programas para a terceira idade no Brasil: Ao mesmo tempo, [os gerontólogos] reforçam o ideal "gerontofóbico" da instituição e a crença de que é possível envelhecer sem ficar "velho". Esse instrumento de confiança ativa [...] faz com que os experts se sintam realmente experts e os idosos como "nãovelhos" (grifo do autor).

Nesse espaço de negação da velhice, as grandes narrativas científicas da saúde perfeita e a gerontologia parecem se encontrar como ideologias: a primeira, a construir efetivamente um certo futuro; a segunda, a contribuir na preparação do terreno para sua boa recepção.

Enfim, parece-nos que gerontologia e a geriatria estariam colocando seu foco, efetivamente, na velhice, identificando-se com a defesa intensa dos interesses dos idosos e com a ação de caráter normativo, articuladas a uma produção de conhecimento ainda primária. De volta a Stengers ${ }^{7}$, a tentativa de captura da velhice por parte da gerontologia deve ser relativizada, com base nas dificuldades conceituais que envolvem a delimitação da velhice. Na busca do estabelecimento de alguma hierarquização dos domínios internos ao estudo da velhice, os limites entre a geriatria e a gerontologia estariam situados mais no campo das profissões: médicos são geriatras e os outros são gerontólogos, presentes aí disputas de espaços pelas corporações envolvidas nesse mundo multidisciplinar. Quanto aos marcos de relacionamentos das demais áreas do conhecimento no estudo do processo de envelhecimento humano, é tão amplo o leque de abordagens, são tantas as interfaces que estão se construindo, que esse fenômeno parece se recusar a ser capturado no seu todo pela gerontologia e/ou pela geriatria. $\mathrm{O}$ envelhecimento parece escorrer pelos vão dos dedos, como algo muito complexo e muito maior do que o possam conceber a geriatria e a gerontologia. 


\section{Envelhecimento e interesses}

Stengers 7 nos abre interessante perspectiva de discussão, ao introduzir a questão dos interesses na produção científica. Em suas palavras: Os conceitos operam sempre por captura: "de direito tudo isso é meu”. E o sucesso da operação de captura depende do tipo de interesse que ela suscita. Se não suscita nenhum, ela aparecerá como delirante, megalomaníaca. Se suscita interesse apenas entre os não-científicos - Estado, indústrias, público -, ela correrá o risco de ser denunciada como ideológica.

No Brasil, a velhice vem suscitando crescente interesse por parte dos mais diferentes setores da sociedade; mas é necessário tentar compreender suas especificidades. A diferenciação de um grupo etário e sua identificação como um problema social importante, a ponto de atrair as atenções de tantos setores da sociedade, são por nós compreendidas como resultado de uma construção social20. Tal processo envolve seu reconhecimento - pressupõe que grupos interessados tenham agido para "produzir uma nova categoria de percepção do mundo social" - e sua legitimação - o que implica uma empresa de promoção para inseri-lo no campo das "preocupações sociais" do momento ${ }^{6}$.

Assim, os determinantes presentes na construção da velhice como problema social devem ser vistos para além das explicações demográficas, como encontramos fundamentando inúmeros artigos que se iniciam informando dados sobre o crescimento da população idosa no mundo e no Brasil. Nesse sentido, Groisman ${ }^{8,9}$ nos auxilia, ao discutir redefinições do curso de vida moderno, através tecnologias de diferenciação que contribuíram decisivamente para a separação da velhice em relação às demais fases da vida no mundo contemporâneo; também precisamos integrar às nossas considerações os estudos de Lopes ${ }^{6}$ acerca da SBGG e de seu papel na formação do campo no Brasil.

Sobre a constituição da geriatria e da gerontologia como campo de saber e de prática profissional, vamos ao século 18 e ao início do século 19, quando os médicos não diferenciavam velhos de jovens. A partir de então, profundas mudanças ocorreram no interior da medicina, com repercussões importantes sobre as concepções de doença e do corpo envelhecido, e um específico discurso sobre a senescência surgiu na França pelas mãos de Bichat, Charcot e Broussais. Não mais as forças cósmicas ou divinas a co- mandar as doenças nos indivíduos; em seu lugar, uma teoria dos tecidos em que o processo de envelhecimento corresponderia a um processo de morte.

A partir do discurso sobre a senescência, surgiu a geriatria, já no início do século 20. A Nascher é atribuída à fundação da especialidade médica - a geriatria -, que se orientava pela tese do envelhecimento como um processo de degeneração celular. É a captura da velhice pela medicina.

Lopes $^{6}$ chama a nossa atenção para o subtítulo do livro publicado por Nascher - Geriatrics: the diseases of old age and their treatment, including phsycological old age, home and institucional care, and medico-legal relations -, vendo nele uma ampla abordagem multidisciplinar. Uma perspectiva que apenas tomará corpo a partir da década de 1940, mas que também esteve presente nas idéias de Metchnikoff, seguidor de Charcot, que criou o termo gerontologia em 1903, para designar, inicialmente, o estudo do prolongamento da vida por meio dos recursos gerados pela medicina. As idéias de Nascher e a criação de um novo campo do saber encontraram, então, fortes resistências na cultura que marcava a ciência e a medicina, particularmente a concepção das disciplinas como bem delimitadas, isoladas, cujas fronteiras eram consideradas intransponíveis. Podemos pensar que as concepções de Nascher e de Metchnikoff encontravam-se na contramão das tendências que viam na especialização por meio de disciplinas ou de áreas específicas do conhecimento os caminhos do progresso da ciência.

No Brasil, encontramos os esforços da SBGG, numa primeira etapa (1960-1970), para a constituição da geriatria como especialidade médica no interior de hospitais cariocas. Momentos de busca, ainda que infrutífera, de parcerias com as universidades, com vistas ao reconhecimento da nova especialidade como um campo científico do conhecimento, até então vista por muitos como marcada pelo charlatanismo dos médicos que exploravam os velhos nos asilos. $\mathrm{E}$ indica ainda a perspectiva de sensibilizar o Estado para a questão da velhice no Brasil, contribuindo para lhe dar visibilidade em relação ao poder público.

A segunda etapa dessa trajetória se refere à década de 1980. O cenário internacional era de sensibilização para a questão do envelhecimento, abordada na Assembléia Mundial do Envelhecimento (AME) - realizada em Viena, em 1982. No caso brasileiro, um desdobramento 
da AME correspondeu à ação, por parte do Governo Federal, no sentido da constituição de uma Política Nacional do Idoso ${ }^{21}$, processo que contou com a participação da SBGG. Vários eventos foram implementados, médicos e vários outros profissionais foram formados por ação da entidade, que se interiorizou, formando novas parcerias com governos estaduais e prefeituras. Foi a era da multidisciplinaridade, da incorporação da gerontologia pela geriatria.

$\mathrm{Na}$ terceira etapa, correspondente à década de 1990, a sociedade brasileira demonstrava crescente sensibilidade para o problema da velhice; inúmeros serviços especializados foram criados; programas para a terceira idade brotaram nas universidades, nas prefeituras, em diversas instituições; centros de estudo, programas de pós-graduação, residências, estágios, orientações curriculares; entidades civis voltadas para idosos, cuidadores e familiares; políticas e programas cada vez mais específicos, etc. Nas palavras de Lopes6: Chegamos no começo do século 21 com a certeza de poder afirmar que a velhice como questão pública é resultado da mistura de elementos que contribuíram para o fortalecimento do seu status como problema social. A SBGG, portanto, por participar intensamente do processo de criação e legitimação da velhice como problema social passa a atuar, na década de 1990, como um dos responsáveis na gestão da velhice e do envelhecimento no Brasil, pois concomitantemente à criação de problemas sociais nascem também as demandas provenientes de tais problemas, que devem ser de preferência solucionados por especialistas naquele assunto. Mais do que nunca a SBGG sente a necessidade de se fortalecer como entidade científica (grifo nosso).

A busca da sua legitimação como campo da ciência; a busca do poder com base em autoridade cientificamente estabelecida: eis uma forte marca da trajetória da SBGG e da geriatria e da gerontologia nacionais, intensificada de 1990 até os dias atuais. Procurando combinar discurso científico e defesa dos idosos, elas vêm crescendo no mercado de trabalho, firmandose como autoridade no estabelecimento de normas e condutas na velhice ${ }^{17}$.

A constituição do saber geriátrico-gerontológico no Brasil acontece envolvendo interesses médicos e de diversos profissionais que, concretamente, se voltam desde o início, e em caráter predominante, para a construção de respostas em face da velhice como um problema social. Os interesses dos cientistas brasileiros pela velhice vêm acontecer bem mais recentemente, atraindo ainda poucos pesquisadores prestigiados e experientes na formação de recursos humanos voltada para a produção científica de ponta, e na captação de recursos para implementação de estudos de grande impacto para o conhecimento nacional e internacional.

Quanto à segunda tecnologia de diferenciação, o surgimento das aposentadorias se vincula à necessidade de dar respostas sociais aos operários, que não poderiam garantir sua sobrevivência através do trabalho já em meados do século 19. A associação entre velhice e invalidez, estabelecida nas décadas que se seguiram, determinou a idade como critério de afastamento da produção baseada na força física. Assim, mesmo que apto fisicamente, ao alcançar a idade da aposentaria o trabalhador entra para o rol dos inativos. Por outro lado, funda-se o estatuto do direito à aposentadoria, motivo de novos posicionamentos subjetivos até então impensáveis na história da velhice.

Em torno das aposentadorias e dos direitos dos idosos, um amplo conjunto de interesses tem se acentuado de forma impressionante nas últimas décadas, por meio da abordagem de grandes temas, como a Reforma da Previdência no Congresso Nacional. Além disso, uma série de legislações foi providenciada, entre elas a Política Nacional do Idoso e o Estatuto do Idoso ${ }^{22}$, assim como a implementação de vários programas de cunho social e de saúde destinados à terceira idade, auspiciados tanto pelo Governo Federal como por estados e municípios. Maiores ainda são as demonstrações de preocupação por parte de políticos, que parecem perceber cada vez mais os idosos como eleitorado em potencial.

A terceira tecnologia de diferenciação refere-se aos asilos de velhos. $\mathrm{O}$ fenômeno de separação da velhice em relação à mendicância acontece de forma relativamente simultânea ao momento em que a medicina passa a tratar do homem velho, e pode ser encarado como um processo de medicalização da condição do ser idoso. Em seus primórdios, essa concepção já é socialmente aceita, embora não se tenha ainda consolidado como objeto científico do saber médico $23,24$.

Consideremos também que é indiscutível o aumento da presença dos idosos na mídia e nas mais variadas formas de apelo. A participação de "pessoas idosas" em novelas levadas nos horários nobres, acompanhada de discussões diretas, explícitas, sobre suas mazelas e seus di- 
reitos; personagens da ficção envolvidas inclusive nos momentos em que políticas governamentais específicas bem reais são anunciadas. Filmes e peças comerciais trazendo idosos oferecem produtos que jamais seriam associados à velhice há bem poucos anos. Como cidadãos ou, muito mais intensamente, como consumidores, jamais os velhos foram tão vistos e expostos pelos meios de comunicação. Ademais, no que diz respeito à indústria, a velhice cada vez mais duradoura interessa, por conta de medicamentos relacionados a doenças crônicas e degenerativas, tecnologias e produtos voltados para o tratamento de agravos à saúde associados ao avanço dos anos de vida, além de um amplo leque de produtos e serviços associados à prevenção do envelhecimento.

E, como no caso dos asilos, parece que estamos, mais uma vez, diante da distinção da figura social do idoso acontecendo simultaneamente à intensificação ou expansão de procedimentos médicos, processo em que vemos reforçada a idéia da medicalização da velhice 23,24

No que se refere aos interesses que o envelhecimento desperta nos meios acadêmicos, é importante registrar que nas universidades, públicas ou privadas, muito têm se destacado os programas para a terceira idade. Em levantamento realizado em 2002 no Centro de Referência e Documentação sobre Envelhecimento 25 - da Universidade Aberta da Terceira Idade da Universidade do Estado do Rio de Janeiro -, foram identificados cerca de 150 programas que recebem idosos aos milhares, em atividades de promoção da saúde e de prevenção e tratamento de doenças. Porém, em relação à pesquisa, os resultados dos estudos que mencionamos anteriormente nos dizem que a geriatria e a gerontologia ainda se encontram muito modestas, e terão muito que caminhar para sua consolidação no espaço da produção de conhecimento.

Retornando a Stengers 7 , e pensando na tentativa de captura da velhice, temos que muitos interesses são de fato mobilizados. Da indústria, da mídia, ao ver os idosos como consumidores; dos governos, no sentido das políticas a serem implementadas; dos políticos, que olham para seu eleitorado; dos profissionais, que pensam o mercado de trabalho, as disputas de espaços de atuação; dos gerontólogos (no sentido amplo), que se debruçam sobre o problema social construído em busca de respostas, o que inclui, de modo ainda periférico, a pesquisa científica. A participação da pesquisa geronto- lógica no Brasil, que se iniciou de forma tardia e limitada, deve nos alertar para a possibilidade de que os velhos estejam despertando interesses predominantes entre "os não-científicos Estado, indústrias, público”, colocando a gerontologia sob "o risco de ser denunciada como ideológica"7.

\section{Sobre um projeto político para a geriatria e para a gerontologia}

Stengers 7 nos apresenta exemplo ilustrativo de seus pensamentos sobre a constituição de um projeto político para um campo do conhecimento: o livro L'homme neuronal, que corresponde a um manifesto político e que coloca pretensões conceituais de organização das ciências. Afirma que as ciências humanas estavam em compasso de espera, aguardando definições sobre os neurônios, de forma a mostrar sua eficácia geral sobre o cérebro e as atividades humanas. Alguns campos das ciências humanas resistiram, por conta de suas capacidades políticas e institucionais, mas alguns ramos da biologia perderam financiamentos, que foram redirecionados para a neurofisiologia. Segundo a autora: É assim que uma operação de captura conceitual freqüentemente tem êxito: quando aqueles que representavam outras relações com aquilo que está em questão vegetam por falta de crédito, não atraem mais os pesquisadores ambiciosos, acabam às vezes desaparecendo ou são substituídos por pesquisadores de um tipo novo, que tentam dar início ao programa conceitual desde então dominante 7 .

No campo do envelhecimento, tomaremos a construção do pensamento de Sá10, que não se pretende ambicioso a ponto de traçar os rumos das ciências ou de se apresentar como um projeto político, mas que, diante da carência de estudos aprofundados sobre a natureza epistemológica da gerontologia, propõe referências, buscando estabelecer a que tipo de ciência corresponde, se formal ou se técnica, e que teorias e metodologias a sustentariam.

Então, defendendo sua natureza eminentemente interventiva, dada sua "razão de ser" para a sociedade - que estaria condicionada a questões sociais expressivas, como: 1) o envelhecimento populacional e sua implicação nas políticas sociais de saúde, previdência social e assistência social; 2) as desigualdades sociais em suas relações com a expectativa de vida; e 3) a cidadania e a luta permanente por direitos 
fundamentais, inclusive na velhice -, Sá entende estar a gerontologia (no sentido amplo) mais próxima das ciências tecnológicas, como a medicina, a arquitetura, a engenharia e o serviço social. Sua marca interdisciplinar a encaminharia para teorias e metodologias em construção, resultantes de inter-relações dinâmicas com diversos outros campos do conhecimento.

Assim, ao reivindicar para si o espaço de uma ciência técnica que deve responder a demandas de um problema social, parece que a gerontologia deve se ater ao espaço da construção de respostas, de ações diante do desafio identificado. Essa perspectiva fica bem clara quando a autora se pergunta: A gerontologia pretende intervir no processo do envelhecimento de modo a provocar mudanças, ou apenas se contentar em conhecer e prever, deixando ao encargo de outras ciências a ação propriamente dita? (grifo nosso).

Ao formular sua pergunta, no contexto de proposta de constituição de uma ciência técnica, a autora dá margem à leitura de uma sobrevalorização da ação, em defesa de um projeto intervencionista, como se fora pouco "apenas [...] conhecer e prever". Antes de tudo, consideramos que a produção do conhecimento se relaciona com a ação por meio de consensos, conflitos e contradições, que não levam, necessariamente, à previsão. Entendemos também que a produção do conhecimento (apenas esta parcela da tríade conhecer, prever e agir indicada pela autora) corresponde, em si, a um imenso empreendimento, que deve inclusive estudar, de forma aguda, as ações implementadas no campo em questão. Feita a ressalva, observamos que essa formulação da gerontologia como ciência técnica, em sua ênfase na ação, como proposição política e como projeto político para um campo do conhecimento, apresentase esmaecida, pouco arrojada diante da grandiosidade que representa o estudo do homem que envelhece. Tem, por desdobramento, menores chances de atrair pesquisadores ambiciosos e recursos financeiros para a implementação de pesquisas de grande repercussão.

\section{Considerações finais}

Enveredamos por esses caminhos a partir de estudos de natureza mais descritiva sobre a pesquisa relativa ao envelhecimento no Brasil, que nos colocaram algumas inquietações: a visualização de fragilidades importantes na qualifica- ção dos pesquisadores brasileiros que se dedicam a essa temática e na sua produção científica; e a identificação de um discurso sobre a gerontologia como campo novo da ciência, cujo amadurecimento virá em função do trabalho de seus pesquisadores.

Os conceitos de envelhecimento e de velhice parecem ser muito mais complexos do que podem conceber a geriatria e a gerontologia, o que se coloca como importante limitação na tentativa de sua captura por parte desse pretenso campo da ciência. As dificuldades identificadas para, por exemplo, delimitar o início do processo de envelhecimento e da velhice, implicam importantes nebulosidades nos domínios que se tenta organizar (a gerontologia, no sentido amplo, e seus ramos, tais como denominados no Brasil: a gerontologia e a geriatria). Estes parecem se estabelecer mais por critérios relativos a identidades profissionais, questões corporativas e disputas de mercado de trabalho, do que por derivação de uma organização conceitual.

Stengers considera que os conceitos operam por captura, definindo, por esse processo, o que de direito pertence a um campo do conhecimento. Considera também que o sucesso da operação de captura depende do tipo de interesse que ela suscita. Por conta do investimento na construção da velhice como problema social, parece-nos que o grande foco de interesses no âmbito das discussões gerontológicas encontra-se mais situado na velhice do que no envelhecimento ou no homem que envelhece. Isso pode ser notado inclusive no próprio argumento demográfico, o mais utilizado para fundamentar a necessidade de atenção para o problema do envelhecimento populacional: o problema diz respeito ao aumento da população idosa, ao envelhecimento dos idosos, e não ao processo de envelhecimento humano desde o seu início.

O maior interesse, quando se trata de gerontologia, parece recair sobre a população idosa. Ainda nesse sentido, consideramos pertinente a crítica de Groisman ${ }^{9}$, quando discute as perspectivas de prevenção em geriatria debatidas em mesa-redonda no congresso da SBGG, realizado em 2000, que tratava da necessidade da prevenção geriátrica desde os 60 anos, desde a idade adulta, desde a adolescência e inclusive na gravidez. Diz o autor: A prevenção parece ser a saída encontrada pela gerontologia, para escapar ao binômio saúde/doença. Com o discurso da "prevenção", todos os sujeitos são passíveis de in- 
tervenção, independente do seu estado de saúde ou inserção na "normalidade". Pela urgência da prevenção, não importa também quando começa a velhice, pois a prevenção deve começar muito antes dessa. Lutando por um envelhecimento "bem-sucedido", a geriatria/gerontologia parece delinear o seu mais ambicioso projeto, que é disciplinar a vida humana em sua extensão.

Por meio da prevenção, a geriatria parece reafirmar mais os interesses corporativos de ampliação do mercado de trabalho do que a produção de conhecimento acerca do processo de envelhecimento. Mas se essa perspectiva preventivista da geriatria não suscitar interesse significativo por parte da população não idosa e dos governos, ela poderá ser vista como quem tenta ir além de suas possibilidades. Se suscitar interesse apenas entre os não-científicos, insistimos, correrá o risco de ser denunciada como ideológica.

A seu favor, a gerontologia nacional investe em diversos interesses. Estado, indústrias e população idosa têm se manifestado em efusivos discursos voltados para esse problema social: a velhice. Os cientistas, ao menos nos dias atuais, vêm demonstrando crescente interesse pelas temáticas do envelhecimento e da velhice, mas não necessariamente, e nem de modo predominante, na condição de gerontólogos ou colocando-se nesse campo. Os grupos de pesquisa que se voltam de forma exclusiva para a temática em discussão são, em geral, os mais frágeis, mais carentes de titulação, de experiência em pesquisa e de formação teórica. Ademais, se se mantiverem pautados pela construção de respostas em face do problema social constituído, e distanciados das discussões conceituais - que ainda estão sendo formuladas -, poderão potencializar os riscos de que a ênfase normatizadora arraste a gerontologia para espaços ideológicos. Este é o caso das marcas da negação da velhice já identificadas no discurso gerontológico.

Finalmente, não identificamos um claro projeto político nacional de constituição da gerontologia e da geriatria como novo campo científico, mas sua conformação parece estar em andamento. A gerontologia (no sentido amplo), como uma ciência técnica, caracteristicamente intervencionista, teria pilares teóricos construídos a partir de referenciais provenientes de outras ciências, uma vez que o seu objeto de estudo e de ação engendra dimensões biológicas, psíquicas, sociais, culturais, estéticas ${ }^{10}$.
Ficaram bem evidenciados os esforços dos geriatras e gerontólogos, no sentido de se aproximarem da universidade desde os primeiros passos na trajetória empreendida no Brasil, com vistas à constituição da gerontologia como uma autoridade apoiada na ciência. Stengers 7 afirma que campos que buscam, em nome da ciência, a constituição de sua autoridade, invocam com freqüência seus fundamentos epistemológicos: Com efeito, para que se possa falar "em nome da ciência", é preciso que a ciência exista, é preciso que ela tenha uma autoridade, é preciso que sua autoridade tenha sido fundada sobre uma leitura epistemológica. Os psicólogos behavioristas e os economistas se referem sempre à epistemologia, vocês encontrarão tratados de epistemologia escritos por psicólogos ou economistas para seus alunos, mas muito poucos escritos por físicos, químicos ou biólogos moleculares.

O momento atual de elaboração de um projeto político para a gerontologia está situado no espaço da tentativa de incorporação do discurso epistemológico, numa perspectiva que nos faz pensar, mais e mais, na necessidade de aprofundar a abordagem teórica acerca do conceito que pretende capturar, sob pena de não avançar na constituição de um importante conjunto de pesquisadores brasileiros de ponta, inseridos no cenário internacional da produção de conhecimento sobre o ser que envelhece.

Pudemos perceber que as limitações para que a gerontologia venha a se consolidar como campo de produção de conhecimento científico não são desprezíveis. $\mathrm{O}$ estudo do envelhecimento humano, bem como as propostas de ação que, no limite, conduzem à sua eliminação desejo, sonho e mito presentes em toda a humanidade -, estão em vigoroso curso também em espaços não cogitados pela pesquisa gerontológica brasileira. Lá, nos laboratórios, onde se buscam no genoma respostas definitivas para doenças como o câncer, a obesidade e (por que não?) para a feiúra, a velhice. Lá, nas mesas cirúrgicas experimentais, onde a tecnociência vislumbra um futuro em que plásticas ou implantes, nos braços, olhos, cérebro e células, possam nos conduzir ao prolongamento da vida, com mudanças substantivas em nossos corpos, talvez sempre belos e jovens. Lá, onde a informática, os computadores artificialmente inteligentes possam estar a nós conectados por muito e muito tempo. Pelos séculos dos séculos, na terra ou no espaço. 


\section{Colaboradores}

SD Prado e JD Sayd participaram igualmente na concepção e discussões do objeto de estudo, na redação e revisão crítica do artigo e na aprovação da versão a ser publicada.

\section{Referências}

1. Prado SD. Envelhecimento, ciência e saber: a pesquisa sobre envelhecimento no Brasil [tese]. Rio de Janeiro: IMS/Uerj; 2004.

2. Prado SD, Sayd JD. A pesquisa sobre envelhecimento humano no Brasil: pesquisadores, temas e tendências. Rev C S Col 2004; 9(3):763-72.

3. Prado SD, Sayd JD. A pesquisa sobre envelhecimento humano no Brasil: grupos e linhas de pesquisa. Rev C S Col 2004; 9(1):57-67.

4. Prado SD, Sayd JD. Os programas de pós-graduação em geriatria e gerontologia no Brasil. Textos Envelhecimento 2003; 6(2):31-46.

5. Prado SD, Sayd JD. Os periódicos especializados em geriatria e gerontologia no Brasil. Textos Envelhecimento. [No prelo].

6. Lopes A. Os desafios da gerontologia no Brasil. Campinas: Alíne; 2000.

7. Stengers I. Da racionalidade científica: capturas, eventos, interesses. In: Stengers I. Quem tem medo da ciência: ciências e poderes. São Paulo: Siciliano; 1990. p. 77-109.

8. Groisman D. Velhice e história: perspectivas teóricas. Cad IPUB 1999;1(10):43-56.

9. Groisman D. A velhice, entre o normal e o patológico. Hist Cienc Saude Manguinhos 2002; 9:(1)61-78.

10. Sá JLM. Gerontologia e interdisciplinaridade: fundamentos epistemológicos. In: Neri AL, Debert GG, organizadores. Velhice e sociedade. Campinas: Papirus; 1999.

11. Neri AL. Palavras-chave em gerontologia. Campinas: Alínea; 2001.

12. Veras, RP. País jovem com cabelos brancos: a saúde do idoso no Brasil. Rio de Janeiro: Relume Dumará; 1994.

13. Prado SD, Sayd JD. A produção científica sobre envelhecimento e saúde no Brasil. Textos Envelhecimento 2004; 7(2):85-101.

14. Veras RP, Caldas CP. Promovendo a saúde e a cidadania do idoso: o movimento das universidades da terceira idade. Rev C S Col 2004; 9(2):423-32.
15. Sfez L. A saúde perfeita: crítica de uma nova utopia São Paulo: Loyola; 1996.

16. Featherstone M, Hepworth M. Envelhecimento, tecnologia e o curso da vida incorporado. In: Debert GG, Goldstein DM, organizadores. Políticas do corpo e o curso da vida. São Paulo: Mandarim; 2000. p. 109-32.

17. Debert GG. A reinvenção da velhice. São Paulo: Edusp; 1999.

18. Lima MA. A gestão da experiência de envelhecer em um programa para a terceira idade: a Unati-Uerj. Textos Envelhecimento 1999; 2:23-63.

19. Debert GG. A invenção da terceira idade e a rearticulação de formas de consumo e demandas políticas. Rev Bra Cienc Soc 1997; 12(34):39-56.

20. Debert GG. Pressupostos da reflexão antropológica sobre a velhice. In: Debert GG, organizador. Antropologia e velhice. Campinas: Unicamp; 1994. p. 7-30. (Série Textos Didáticos, no 13 ).

21. Lei no 8.842 de 4 de janeiro de 1994. Dispõe sobre a Política Nacional do Idoso. Diário Oficial da União 1994; 5 jan.

22. Lei no 10.741 de 1 o de outubro de 2003. Dispõe sobre o Estatuto do Idoso. Diário Oficial da União 2003; 3 out.

23. Foucault M. O nascimento da clínica. Rio de Janeiro: Forense Universitária; 1980.

24. Foucault M. Microfísica do poder. Rio de Janeiro: Graal; 1986.

25. Centro de Referência e Documentação sobre Envelhecimento. Programas para 3a idade no Brasil [acessado 2004 set 15]. Disponível em: http://www.unati. uerj. br/programa/programas.asp

Artigo apresentado em 27/07/05

Aprovado em 21/11/2005

Versão final apresentada em 15/03/2006 